\title{
Asymptomatic levo uterine torsion of 90 degrees during caesarean section
}

\author{
Sirisha Anne ${ }^{1 *}$, Arpit Garg ${ }^{2}$, Debraj Sen ${ }^{3}$ \\ ${ }^{1}$ Department of Obstetrics and Gynecology, ${ }^{2}$ Department of Anaesthesiology, ${ }^{3}$ Department of Radiology, Armed \\ Forces Medical College, Pune, Maharashtra, India
}

Received: 07 August 2017

Accepted: 31 August 2017

*Correspondence:

Dr. Sirisha Anne,

E-mail: siri1407@gmail.com

Copyright: ( $)$ the author(s), publisher and licensee Medip Academy. This is an open-access article distributed under the terms of the Creative Commons Attribution Non-Commercial License, which permits unrestricted non-commercial use, distribution, and reproduction in any medium, provided the original work is properly cited.

\begin{abstract}
Uterine torsion is defined as a rotation of uterus more than 45 degrees along it's long axis. Some degree of dextrorotation in the gravid uterus can be a normal finding, however rotation greater than 45 degrees along the longitudinal axis of the uterus which is described as uterine torsion is a rare pathological condition in obstetrical practice. We report a case of levotorsion of the uterus by 90 degrees wherein patient had presented with pre term labour at 35W5D POG and levotorsion was encountered and managed intraop during caesarean. Uterine torsion of 90 degrees was encountered with the round ligament and tubo ovarian complex along with the uterine artery lying anteriorly at the incision site and lower segment of uterus rotated laterally onto the right side. The surgery was handled diligently resulting in average blood loss. Blood loss during the surgery was average. After the delivery of the baby, uterus returned to anatomical position and levotorsion corrected spontaneously.
\end{abstract}

Keywords: Caesarean, Levotorsion of uterus in pregnancy, Uterine torsion

\section{INTRODUCTION}

Uterine torsion is a complication rarely encountered by the obstetrician, often not being diagnosed until just before or just after delivery at caesarean section. It is associated with morbidity and mortality both for the mother and the baby. The etiology of uterine torsion in most cases is unknown. Literature search suggests case reports only and mostly experiencing 180 degrees rotation of the uterus. ${ }^{1}$ Uterine torsion in many case reports suggests dextro rotation whereas in our case it was levotorsion of 90 degrees which has not been reported till date. It has been studied to be associated with fetal compromise also. Perinatal mortality has been reported to be around $12 \%$ and occasional maternal mortality reported. ${ }^{2}$ Only in about $16 \%$ cases cause has not been associated, the other causes associated with torsion were uterine asymmetry, uterine anomalies, and severe adhesions from pelvic surgeries. ${ }^{1}$

\section{CASE REPORT}

A 29-year-old lady, G3P1L1A1, at 35W5D POG was admitted with complaints of pain abdomen and low back ache since one day. Her first pregnancy was a spontaneous abortion at 12 weeks. Second pregnancy was two years ago when she underwent emergency LSCS at term for non progress of labour and delivered a baby with birth weight of $3 \mathrm{~kg}$ However during the previous LSCS there was no history suggesting she had uterine torsion intraop. Her pregnancy had been uneventful throughout with no any other co morbidities. At admission, her vitals were stable and abdominal examination revealed abdomen unusually distended with cephalic position of the fetus and uterus was relaxed. NST was reactive. She was observed in the ward for monitoring of her labour. The next day patient complained of increased abdominal discomfort. Her examination then showed that she had 
uterine contractions, for which she was taken up for emergency LSCS, indication being post LSCS in labour.

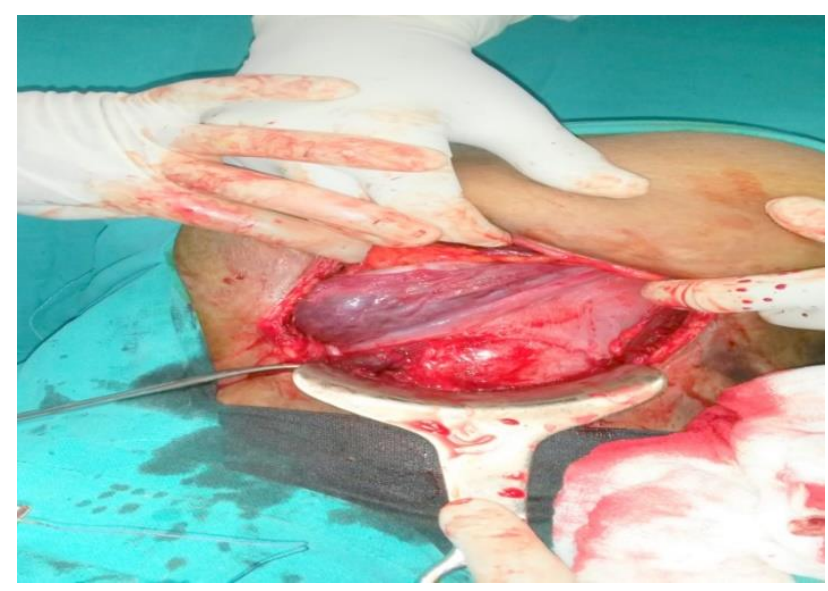

Figure 1: A view of the uterus when abdomen was opened. The round ligament, fallopian tube and ovary lying anteriorly in the midline.

Intraop the diagnosis of levotorsion of uterus was made due to the round ligament and tubo ovarian complex of the right side were rotated to the left side and were lying anteriorly detorsion was attempted but unsuccessful. The uterine arteries and veins were lying anteriorly which were dissected carefully and ligated in anticipation of blood loss due to extension of the uterine incision.

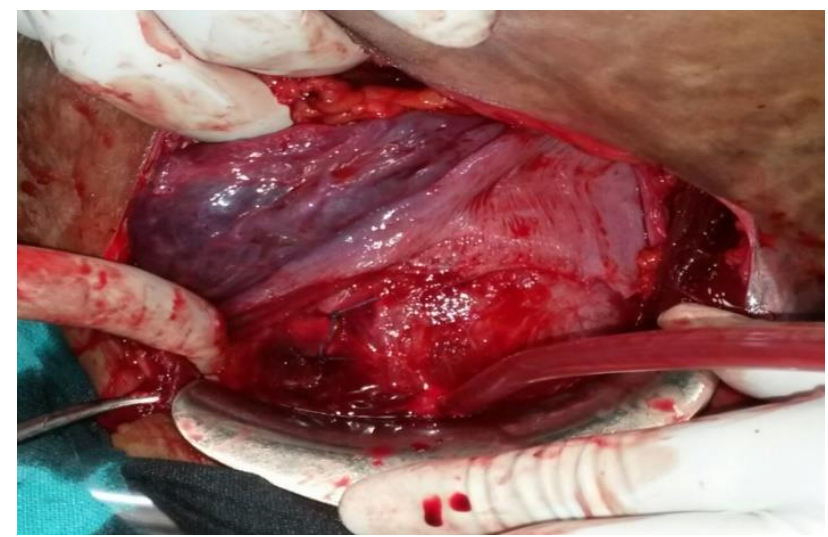

Figure 2: The uterine artery and vein lying anteriorly in the midline were dissected and ligated.

The $\mathrm{U} \mathrm{V}$ fold of peritoneum was identified and cut and bladder pushed down. the lower segment was accessed vertically since it was a 90 degrees torsion. Utmost care was taken to extend the uterine incision only to the left side so that uterine arteries lying anteriorly are not affected. Baby weighing $2.35 \mathrm{~kg}$ was born with normal APGAR. After the delivery of the baby placenta was delivered after ten minutes, requiring manual removal of placenta since placenta was not separated. Uterus was sutured in single layer and haemostasis ensured. The uterus had returned to its anatomical position following the delivery. Blood loss during the surgery was about 800 ml. No uterine anomalies or fibroids were seen in the uterus. No adhesions witnessed intraop. Routine closure of the abdomen was then completed. Abdomen was examined post operatively and was found to be extremely lax. Post op period was uneventful and was discharged on the fourth day. On follow up patient has been asymptomatic for recurrence of torsion.

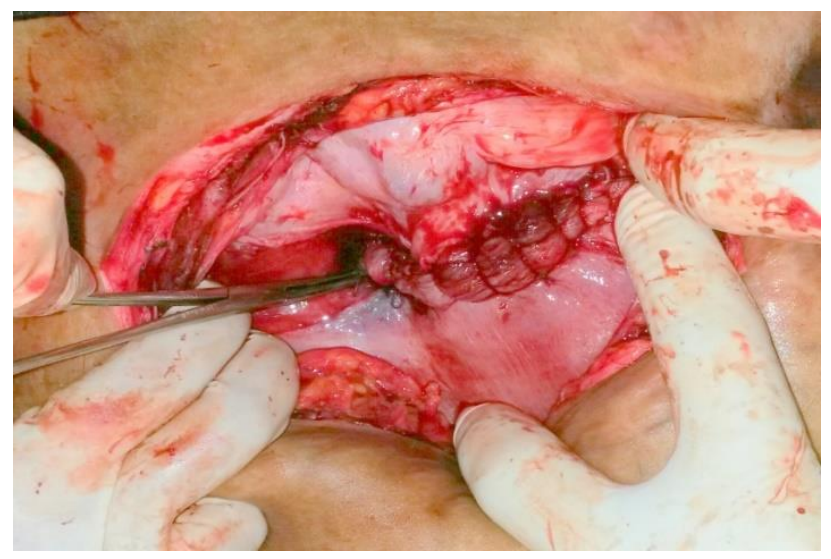

Figure 3: The view of the uterus after the delivery showing the detorsion of the uterus. The instrument in the picture points to the uterine artery which was not injured in the surgery with the incision just reaching the uterine artery.

\section{DISCUSSION}

Uterine torsion is a rare complication of pregnancy which is more often an intra op diagnosis during LSCS. The rotation can range between 60 degrees to 720 degrees with most cases in pregnancy being around 180 degrees. ${ }^{2}$ It occurs at the junction between the cervix and the uterine corpus. Slight rotation of the uterus is common during pregnancy but rarely exceeds $45^{\circ}$ and is most often to the right. Uterine torsion is associated with perinatal mortality around $12 \%$. Maternal mortality is studied to be as $1 \%$ and is directly proportional to degree of torsion and gestational age. ${ }^{2}$

The cause of uterine torsion in most cases is unknown. A case series by Piot ET AL described a number of possible associative and causative factors: $32 \%$ cases had a fibroid uterus, $15 \%$ had other uterine anomalies such as a bicornuate uterus, $8 \%$ had pelvic adhesions, $7 \%$ had ovarian cysts or other adnexal masses, $5 \%$ had abnormal fetal presentation and fetal abnormalities were identified in $3 \%$ cases. In this series, over $30 \%$ cases had no cause identified. $^{2}$

More recent studies with no identified causative pelvic factors have suggested previous caesarean section as a common feature, and MRI of patients after caesarean section has suggested that poor isthmic healing, resulting in an elongated cervix with structural weakness and angulation may predispose to torsion of the uterus. Presentation of uterine torsion has been studied to be independent of maternal age, parity and gestation. 
Uterine torsion is difficult to diagnose preop since presenting symptoms and signs are non specific and can mimic other situations like scar dehiscence and abruption placentae. Ultrasound can also help in diagnosing uterine torsion antenatally by the following features. ${ }^{3}$

- Transposition of placental bed compared to previous scan

- Doppler recognition of ovarian vessels anterior to the uterus

MRI has been reported to help in diagnosing uterine torsion antenatally by the demonstration of $\mathrm{X}$ shaped configuration in the upper vagina. ${ }^{6}$ However in our case the patient was asymptomatic and hence we could not diagnose it antenatally.

Review of literature has a case report publishing pre term labour at 32 weeks with abruptio placenta. In our case patient has been asymptomatic till 35W5D POG. Placenta delivery was not difficult in all the case reports reviewed, however in our case placenta was not completely separated and required manual removal of placenta. ${ }^{4}$ Literature suggests two-third cases with dextro rotation of the uterus which eventually is an exaggeration of physiological rightward shift of the uterus and mostly being rotated by 180 degrees requiring posterior hysterotomy. ${ }^{5}$ In our case uterus was levo rotated which is rare and degree of rotation was also 90 degrees which has not been reported in literature as per our knowledge.

The management of a uterine torsion in a near-term viable gestation is delivery by caesarean section, and detorsion of the uterus, thereby preventing the risk of deterioration of the mother and fetus. The benefit of making the diagnosis prior to the uterine incision is that an attempt could be made to detort the uterus prior to delivery, thereby preventing a posterior uterine wall hysterotomy. In this case, uterine torsion was diagnosed intraop and detorsion attempted which was unsuccessful. The uterine artery and vein lying anteriorly were dissected and ligated carefully near the incision site to avoid blood loss. The incision on the uterus had to be taken vertical to avoid the uterine arteries lying anteriorly ,a technique which has not been described before .It was not until after delivery of the fetus that the uterus was detorted along its longitudinal axis, as it was not possible to detort the uterus In all cases of uterine torsion ,detorsion should be attempted to avoid post wall hysterotomy.

The incidence of repeat uterine torsion or uterine rupture (resulting from posterior uterine wall hysterotomy) in subsequent pregnancy has not been studied. Therefore, women with uterine torsion should be advised to have repeat caesarean delivery in any future pregnancy. Bilateral plication of round ligaments has been reported as a prophylactic measure to avoid recurrence of torsion.

\section{CONCLUSION}

Uterine torsion is a complication which is rarely encountered by the obstetrician often not being diagnosed pre operatively. An extremely lax abdomen during first trimester might help in suspecting uterine torsion in due course of pregnancy. Identification of anatomical landmarks can guide the surgeon to diagnose uterine torsion intra operatively and approach to the lower segment can be planned. In cases of levotorsion of 90 degrees it is imperative to ligate the uterine vessels to avoid rupture of these vessels and take a vertical incision on uterus thereby avoiding traumatic haemorrhage. Detorsion must be attempted in all cases if possible.

Funding: No funding sources

Conflict of interest: None declared

Ethical approval: Not required

\section{REFERENCES}

1. Farhadifar F, Nikkhoo B, Shahgheibi S, Soofizadeh $\mathrm{N}$, Rezaie M. Asymptomatic uterine torsion in a pregnant woman. Indian J Surg. 2014;76(4):321-2.

2. Moores KL, Wood MG, Foon RP. A rare obstetric emergency: acute uterine torsion in a 32-week pregnancy. BMJ case reports. 2014;2014:bcr2013202974.

3. Ulu I, Güneş MS, Kiran G, Gülşen MS. A rare cause of placental abruption: uterine torsion. JCDR. 2016;10(1):QD06.

4. Zullino S, Faiola S, Paganelli AM, Ferrazzi E. A case of abruptio placentae due to the torsion of gravid uterus. Case Rep Obstet Gynecol. 2014;2014:801616.

5. De Loris A, Pezzuto C, Nardelli GB, Modena AB. Cessarean delivery through posterior hysterotomy in irreducible uterine torsion: case report. Acta Biomed. 2010;81(2):141-3.

6. Nicholson WK, Coulson CC, Mc Roy MC, Semelka RC. Case report-Pelvic magnetic resonance imaging in the evaluation of uterine torsion. Obstet Gynecol. 1995;5pt2:888-90.

Cite this article as: Anne S, Garg A, Sen D.

Asymptomatic levo uterine torsion of 90 degrees during caesarean section. Int J Reprod Contracept Obstet Gynecol 2017;6:4700-2. 